\title{
Growth and mortality of the oceanic squid Sthenoteuthis oualaniensis (Lesson, 1830) off south-west coast of India
}

\author{
A. JOHN CHEMBIAN AND SALEENA MATHEW* \\ Chennai Base of Fishery Survey of India, Fishing Harbour Complex, Royapuram, Chennai - 600013 \\ Tamil Nadu, India \\ "School of Industrial Fisheries, Cochin University of Science and Technology, Fine Arts Avenue \\ Kochi - 682 016, Kerala, India \\ e-mail :johnchembian@yahoo.co.in
}

\begin{abstract}
The study attempted to understand the difference in growth and mortality rate, between two phenotypic variants of the oceanic squid Sthenoteuthis oualaniensis. Specimens (1015 nos.) of the species collected off the south-west coast of India (lat. 07 to $11^{\circ} \mathrm{N}$; long. 74 to $77^{\circ} \mathrm{E}$ ) at a depth range of $180-2601 \mathrm{~m}$ were used in this study. Data on dorsal mantle length (DML) of dwarf and medium forms of the species were collected and analysed using the length-based FiSAT routine. $\mathrm{L}_{\infty}$ varied from 17.37 to $18.05 \mathrm{~cm}$ with an average of $17.89 \mathrm{~cm}$ for the dwarf and 29.5 to $30.49 \mathrm{~cm}$ with an average of $30.08 \mathrm{~cm}$ for medium form. Dwarf forms had a higher average $\mathrm{K}$ value $\left(3.65 \mathrm{~cm} \mathrm{y}^{-1}\right)$ with $\pi$ of 3.06 , whereas, medium form had a lower average $\mathrm{K}$ value $\left(2.38 \mathrm{~cm} \mathrm{y}^{-1}\right)$ with $\pi$ of 3.33. Growth curve and longevity study indicated longer than a year life span for medium forms (461 days) with growth rate of $13.3 \mathrm{~cm}$ DML in three months (91 days), $20.8 \mathrm{~cm}$ in six months (182 days) and $25.0 \mathrm{~cm}$ in nine months (273 days). Dwarf form attained maximum length in ten months (302 days) with a growth of $10.5 \mathrm{~cm}$ in three months (91 days), $14.9 \mathrm{~cm}$ in six months (182 days) and $16.7 \mathrm{~cm}$ DML in nine months (274 days). The average total instantaneous mortality ( $\mathrm{Z}$ ) was estimated as $4.58 \mathrm{y}^{-1}$ for dwarf and $6.03 \mathrm{y}^{-1}$ for medium form. As there was no commercial fishing for this species, fishing mortality was considered nil. Therefore, total mortality rate $\mathrm{Z}$ was considered equivalent to natural mortality.
\end{abstract}

Keywords: Dwarf form, Growth, Medium form, Mortality, Purple back squid, Sthenoteuthis oualaniensis

\section{Introduction}

Existing studies on the growth function of cephalopods are not consistent and mostly indicate exponential, linear and asymptotic phases, with or without seasonal oscillation (Miyahara et al., 2006). However, the peculiar life history of squids and the impact of environment on its growth may prove otherwise. The linear or quasi-linear growth indicated in many studies may be attributed to the cephalopod paedomorphic life history (Yatsu, 2000) and the overestimation of its growth rate based on statolith ring (Hatfield, 2000). These rings are dark and proteinaceous, formed in response to feeding activity that often has a regular dial basis (Radtke, 1983). Therefore, factors such as temperature (Villanueva, 2000; Chung and Lu, 2005), age (Bettencourt and Guerra, 2001), body size (Hussy, 2008a), activity level, pH (Morris, 1991) and feeding level (Hussy, 2008b) are all known to influence the accretion process of statoliths and thereby its legibility. Besides, oxygen limitation also leads to blurred areas without rings towards the margins of the statoliths of older squid. Indeed, this may be the very reason why "linear" growth curves often emerge from size at age data based on age readings presumed to be daily.

In addition to that, the elimination of many older specimens from the population due to strong post-spawning mortality also contributes to the postulation of the initial linear or log-linear segments of growth curves as the total growth curve of the squid. As a consequence, a serious underestimation of the real age (Pauly, 1998) and overestimation of the growth rate of the squid is done. Moreover, this is in contrast with the growth curves of cephalopods raised in captivity (Forsythe and Van Heukelem, 1987), where the increase in the growth rate mimic logarithmic growth during the juvenile phase of the squid, which then decline as it approaches asymptotic. However, this second phase is often not visible in wild, perhaps due to mortality and possibly due to paedomorphosis and the aging bias indicated earlier. The asymptotic growth model on the contrary, is an ideal prediction model for the growth, as it is the net result of a volume to surface relation (von Bertalanffy, 1951) and constructs the growth curve by length modal progression analyses (MPA). Verrill 
(1882) first used this modal analysis method for estimating growth rates of cephalopods.

Mortality in this species is entirely by natural cause, due to the non-existence of directed fishing. Hence, natural mortality $(\mathrm{N})$ is considered equivalent to total mortality rate $(\mathrm{Z})$ i.e., $\mathrm{Z}=\mathrm{M}$ (Sinclair, 2001). Predation is probably the most important cause for natural mortality as indicated by the prevalence of this species in the diet of many large fishes, marine mammals and many sea birds that forage within its habitat. Clarke (1983) estimated that sperm whales alone consume $>100$ million $t$ of squid annually. Besides predation, squids meet one third of their maintenance food requirement by cannibalism. It is generally assumed that post-spawning mortality in cephalopods is very high and occurs due to flaccid mantle. Roper et al. (1984) also reported that many species die after spawning, but the phenomenon is apparently not universal.

In Indian waters, apart from a study on its phenotypic variants in the south-west coast of India (Chembian and Mathews, 2014) and a preliminary estimate by Mohamed et al. (2006), no published works are available on the growth and mortality of Sthenoteuthis oualaniensis. In view of the above facts, this study has been attempted through the available methods of the length based routine of FiSAT software.

\section{Materials and methods}

Specimens of $S$. oualaniensis were collected from the south-west coast of India (lat. 07 to $11^{\circ} \mathrm{N}$; long. 74 to $77^{\circ} \mathrm{E}$ ) in the depth range of $180-2601 \mathrm{~m}$ (Fig. 1)

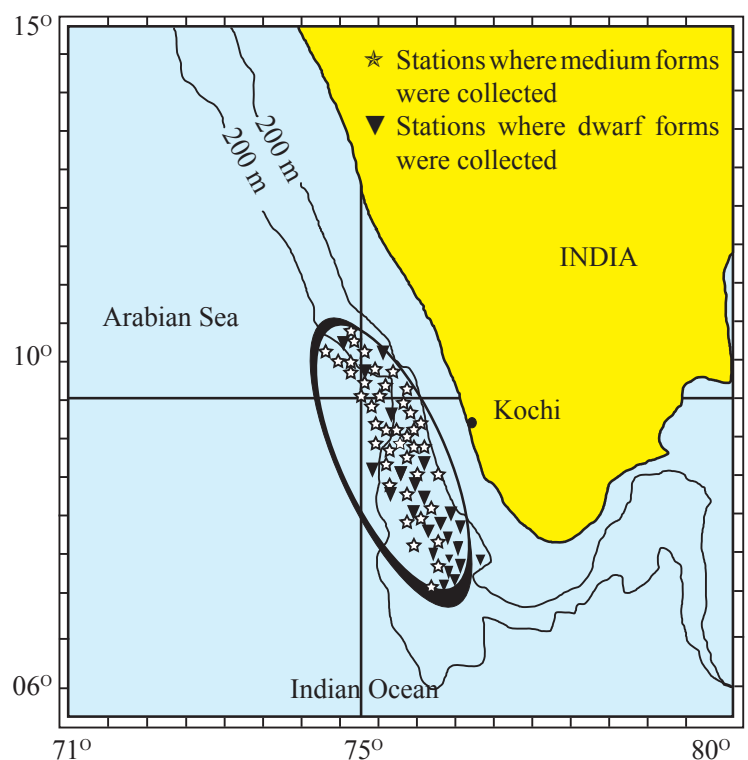

Fig. 1. Map of the south-west coast of India showing the oceanic squid sampling area during the study period. during January 2007-December 2008. Matsya Sugundhi (31.5 m OAL, 245.8 GRT and 650 BHP), a long linercum-squid jigger of the Fishery Survey of India (FSI) and the 44-60 feet gill netters/tuna longliners of the Cochin based Colachal fishing fleet were the prime source for collection of samples. Matsya Sugundhi employed an automatic squid jigging machine, while the fishing boats employed handline with jigs to collect samples. No sampling was done during July, due to the 45 days fishing ban from June $15^{\text {th }}$ to July $30^{\text {th }}$ for mechanised fishing vessels, along the west coast of India.

A total of 1015 specimens were collected during the study. On the basis of the description provided by Nesis (1993), two forms of $S$. oualaniensis were identified from the samples, medium form with dorsal mantle length (DML) ranging from 9.8 to $27 \mathrm{~cm}$ and dwarf form with the DML in the range of 9.1 to $16.5 \mathrm{~cm}$. Out of the 1015 specimens collected, 565 were of the medium and 450 were of the dwarf form. Specimens were thawed and measured for DML, from the tip of dorso-posterior end to the tip of the dorso-anterior end of the squid mantle. Measurements were made separately to the nearest millimeter for the dwarf and medium forms. Though S. oualaniensis are sexually dimorphic (Chembian and Mathews, 2014), with females growing larger than males, due to the poor representation of males in the sample, sex-wise analyses could not be done and only indicative study on the growth of the dwarf and medium forms were conducted with the available samples. In some of the months, sufficient samples could not be collected due to the non-availability of species in the fishing area. In view of that, data collected during 2007 and 2008 were merged month-wise to increase the sample strength for meaningful study. It was then analysed by length based software, FiSAT II, as has been done by Chakraboty et al. (2013) and Mehanna and El-Gammal (2010) on other cephalopod species.

The output of the monthly data analysed employing Bhattacharya's method (Bhattacharya, 1967) was saved as the "mean and standard deviation" file for further analyses in the FiSAT routine. The mean lengths of the components obtained were plotted against the sampling months and the mean lengths believed to be of the same cohort were linked to create growth increment file (GIN) and length at age file (LAA). As the linking process was highly subjective, previous knowledge on the growth pattern of the squid was helpful in performing the analysis. The GIN file created by linking of means was used as input for the Gulland and Holt, Munro's and Fabens routines of FiSAT to calculate the $\mathrm{K}$ value and the $\mathrm{L}_{\infty}$. The asymptotic length $\left(\mathrm{L}_{\infty}\right)$ and $\mathrm{Z} / \mathrm{K}(\mathrm{Z}=$ total 
mortality; $\mathrm{K}=$ growth coefficient) was estimated using the Powell-Wetherall method of FiSAT. The length at age (LAA) file was used as input in the FiSAT routine to study the age at length. Growth parameters were estimated using different methodology and compared to arrive at an acceptable mean value of these parameters separately for the dwarf and medium forms. The $\mathrm{L}_{\infty}$ and the $\mathrm{K}$ value of the Gulland and Holt plot were taken as standard due to its proximity to the average and used as the input in the von Bertalanffy's growth equation

$\mathrm{L}_{\mathrm{t}}=\mathrm{L}_{\infty}\left(1-\exp ^{-\mathrm{k}(\mathrm{t}-\mathrm{t} 0)}\right)$

The results were used to generate the VBGF plot of the FiSAT routine with the oscillation parameter $(C)$ and winter point assumed to be 0 due to its tropical nature. Growth performance index $(\pi)$ was computed using the equation (Pauly, 1984):

$\pi=\log _{10} \mathrm{~K}+2 \log _{10} \mathrm{~L}_{\sharp}$

and Longevity from the following equation:

$\mathrm{t}_{\max }=\mathrm{t}_{0}+3 / \mathrm{K}$

where $t_{\max }$ is the approximate maximum age of the squid in a given population.

The total instantaneous mortality coefficient $(\mathrm{Z})$ was estimated using length-converted catch curve analysis, Jones \& van Zalinge plot, Beverton \& Holt and Ault \& Ehrhardt routine of the FiSAT software. However, for the dwarf form, the length-converted catch curve analysis was not applied for estimating $\mathrm{Z}$ due to insufficient data. As there was no commercial fishing done for this species, fishing mortality was considered nil. As a result, the total mortality rate $\mathrm{Z}$ was considered equivalent to natural mortality $(\mathrm{M})$.

\section{Results and discussion}

Asymptotic length $\left(L_{\infty}\right)$

The $\mathrm{L}_{\infty}$ of the dwarf form was estimated as 17.62 cm DML by the Powell - Wetherall method (Fig. 2a) with the cut-off length $\left(\mathrm{L}^{\mathrm{I}}\right)$ ranging from 12.5 to $15.5 \mathrm{~cm}$ and mean L- $\mathrm{L}^{\mathrm{I}}$ (mean length - cut-off length) ranging from $0.5-1.21 \mathrm{~cm}$. The regression equation for the dwarf was of $\mathrm{Y}=4.18-0.237 \mathrm{X}$ with highly negatively correlated mean L- $\mathrm{L}^{\mathrm{I}}$ and $\mathrm{L}^{\mathrm{I}}\left(\mathrm{r}^{2}=-1.00\right)$. Medium form $\mathrm{L}_{\infty}$ was $29.5 \mathrm{~cm}$ with $\mathrm{L}^{\mathrm{I}}$ ranging from 13.5 to $26.50 \mathrm{~cm}$ and mean L- $\mathrm{L}^{\mathrm{I}}$ ranging from $0.50-3.68 \mathrm{~cm}$. Regression equation for the medium form was $\mathrm{Y}=7.04-0.239 \mathrm{x}$ with mean $\mathrm{L}-\mathrm{L}^{\mathrm{I}}$ and the $\mathrm{L}^{\mathrm{I}}$ being highly negatively correlated similar to that of the dwarf form $\left(r^{2}=-0.951\right)$ (Fig 2b). $\mathrm{L}_{\infty}$ arrived by other methods varied from 17.37 to $18.05 \mathrm{~cm}$ DML with the average of $17.89 \mathrm{~cm}$ for the dwarf and 29.65 to $30.49 \mathrm{~cm}$ with the average of $30.08 \mathrm{~cm}$ for medium form as stated in Table 1 .

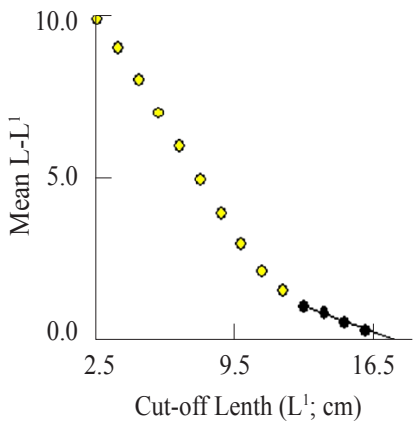

(a)

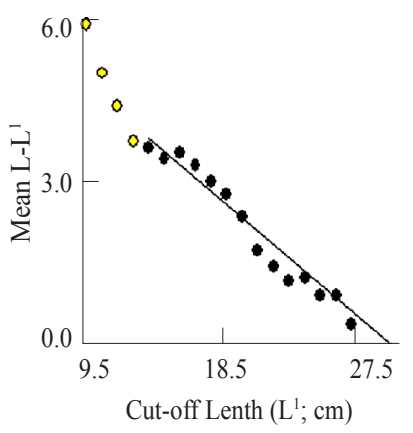

(b)
Power -Wetherall plot

Fig. 2. $\mathrm{L}_{\infty}$ estimation for Sthenoteuthis oualaniensis using (a) Dwarf form, (b) Medium form

Table 1. Growth parameters estimated for Sthenoteuthis oualaniensis of south-west coast of India

\begin{tabular}{|c|c|c|c|c|c|c|c|}
\hline \multirow{2}{*}{ Forms } & \multirow{2}{*}{ Parameters } & \multicolumn{5}{|c|}{ Models } & \multirow{2}{*}{ Average } \\
\hline & & $\begin{array}{l}\text { Powell } \\
\text { Wetherall }\end{array}$ & $\begin{array}{l}\text { Gulland } \\
\text { and Holt }\end{array}$ & Faben & Munro & $\begin{array}{l}\text { Analysis of } \\
\text { length at age }\end{array}$ & \\
\hline \multirow[t]{5}{*}{ Dwarf } & $\mathrm{L}_{\infty}(\mathrm{cm})$ & 17.62 & 18.05 & 18.05 & 18.37 & 17.37 & 17.89 \\
\hline & K year ${ }^{-1}$ & & 3.48 & 4.07 & 3.24 & 3.82 & 3.65 \\
\hline & $\phi$ & & 3.05 & 3.12 & 3.04 & 3.06 & 3.06 \\
\hline & $\mathrm{t}_{0}$ & & 0.0 & 0.0 & 0.0 & 0.0 & 0.0 \\
\hline & $\mathrm{t}_{\max }$ (days) & & 314 & 269 & 337 & 286 & 302 \\
\hline \multirow[t]{5}{*}{ Medium } & $\mathrm{L}_{\infty}(\mathrm{cm})$ & 29.50 & 30.2 & 30.2 & 29.65 & 30.49 & 30.08 \\
\hline & K year ${ }^{-1}$ & & 2.33 & 2.68 & 2.35 & 2.19 & 2.38 \\
\hline & $\phi$ & & 3.33 & 3.39 & 3.3 & 3.3 & 3.33 \\
\hline & $\mathrm{t}_{0}$ & & 0.0 & 0.0 & 0.0 & 0.0 & 0.0 \\
\hline & $\mathrm{t}_{\max }$ (days) & & 470 & 408 & 465 & 500 & 461 \\
\hline
\end{tabular}


Results are in conformity with the previous results from Western Indian Ocean, wherein, the DML ranged from 9.0-18.0 (dwarf form) and 8.0-27.0 cm (medium form) (Trotsenko and Pinchukov, 1994). However, according to Nesis (1993), medium form had a maximum model size of $25 \mathrm{~cm}$ DML and dwarf with a maximum model size of only $15 \mathrm{~cm}$ DML. It was also suggested that the dwarf form could be a separate species and could be identified only as an adult (Xinjun et al., 2007). Meanwhile, attempts were also made to describe these forms as separate species (Clarke, 1965; Wormuth, 1976). A study based on RAPD (Random Amplified Polymorphic DNA) analysis done also indicates large variations in biology among the groups (Xinjun et al., 2007).

\section{Growth parameters}

Growth coefficient (K value) computed using various methods stated in the methodology indicated that dwarf and medium forms have different range of $\mathrm{K}$ values.

\section{Dwarfform}

The growth coefficient ( $\mathrm{K}$ value) of the dwarf form was computed as $3.48 \mathrm{y}^{-1}$ employing Gulland and Holt plot method with an $\mathrm{L}_{\infty}$ of $18.05 \mathrm{~cm}$ DML. The computed $\mathrm{K}$ and $\mathrm{L}_{\infty}$ values for the dwarf form by the Fabens and Munro methods were $4.07 \mathrm{y}^{-1}, 18.05$ and $3.24 \mathrm{y}^{-1}$ and 18.37 respectively. The $\mathrm{K}$ and $\mathrm{L}_{\infty}$ were also estimated with the length at age routine of FiSAT. This indicated a similar trend with $\mathrm{K}$ value as $3.82 \mathrm{y}^{-1}$ and $\mathrm{L}_{\infty}$ as $17.37 \mathrm{~cm}$. The average $\mathrm{L}_{\infty}$ of all the five methods was $17.89 \mathrm{~cm}$ and the average $\mathrm{K}$ value was $3.65 \mathrm{~cm} \mathrm{y}^{-1}$. The high growth rate of the species observed in this study is similar to that indicated by the other studies (Nesis, 1977; Zuev et al., 1985; Xinjun et al., 2007). Sparre and Venema (1996) indicated that higher $\mathrm{K}$ is related to the higher metabolic rate of the species. The metabolic rate is also a function of temperature and tropical species have higher $\mathrm{K}$ values than cold-water species. Growth performance index $(\pi)$ ranged from 3.04-3.12 with an average of 3.06 and the $\mathrm{t}_{\max }$ ranged from 269-337 days with an average of 302 days. The growth performance index $(\pi)$ obtained from different methods were compared and it showed slight variation ranging from 3.04-3.12 for the dwarf form. The growth performance index of 2.58-3.28 calculated for Loligo duvaucelii by Mohamed (1996) off south-west coast of India and the present study are indications of the high growth rate in squid along the south-west coast of India.

The von Bertalanffy's growth equation of $L_{t}=18.05\left(1-\exp \left[-3.48\left(t-t_{0}\right)\right]\right)$ for dwarf and the VBGF plotted (Fig. 3) along with the Faben's growth curve (Fig. 4.) indicates that, dwarf form may attain $\mathrm{L}_{\infty}$ in around ten months. This corroborate the results obtained from the

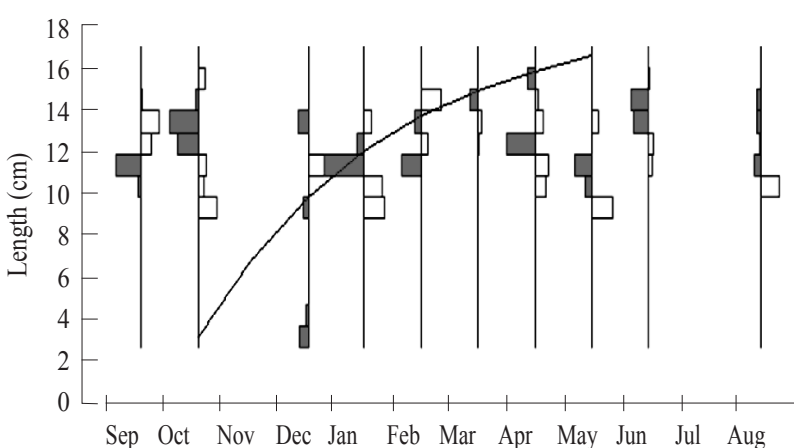

Fig. 3. von Bertalanfy growth curve for $S$. oualanienesis dwarf form with superimposed histograms. The dark and white bars are positive and negative deviations from the weighed model classes representing pseudo cohorts (Months have been rearranged to get the model curve)

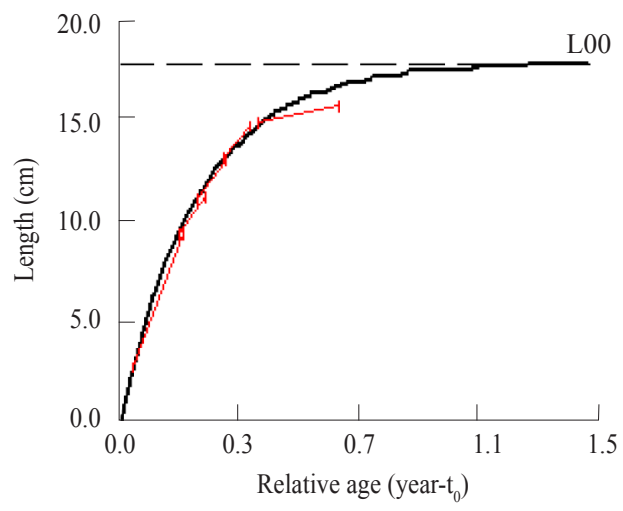

Fig. 4. Fabens growth curve for S oualanienesis dwarf form

$\mathrm{t}_{\max }$ method, where the average longevity obtained was of ten months (302 days) with the average $\mathrm{K}$ value of $3.48 \mathrm{y}^{-1}$. In total, longevity of the dwarf form varied from 269-337 days among the four methods applied (Table 1). Zuyev et al. (1985), noted that the growth parameters estimated through von Bertalanffy's growth equation for the small, early-maturing form of genus Sthenoteuthis indicates its life span to be 1 year. Other studies also support the view that $S$. oualaniensis had its life span less than 1 year (Nesis, 1993; Trotsenko and Pinchukov, 1994). However the study based on the gladius micro structure indicates that the duration of life cycle in the dwarf early-maturing equatorial form of $S$. oualaniensis was only about 6 months (Zuyev at al., 2002).

From the growth curve it is evident that growth is faster in the first half of life when compared to the second half, as $75 \%$ of the growth is achieved in the first five months time. However, it takes another four months to achieve the remaining $25 \%$ of the growth indicating a slower growth rate in the later phase. Growth rate of the dwarf form computed from Gulland and Holt plot was 0.11 for the mean length of $6.34 \mathrm{~cm}, 0.061$ for the mean 
length of $10.61 \mathrm{~cm}, 0.058$ for the mean length of $12.42 \mathrm{~cm}$, 0.055 for the mean length of 14.55 and 0.011 for the mean length of $15.50 \mathrm{~cm}$. This indicates a decreasing rate of growth from the juvenile to adult. Lipinsky and Roeleveld (1990) says that squid displays a form of asymptotic growth, well represented by the standard von Bertalanffy model with growth rates that declined linearly with length. It is estimated that dwarf grows approximately $10.5 \mathrm{~cm}$ in DML in three months (91 days), $14.9 \mathrm{~cm}$ in six months (182 days ) and $16.7 \mathrm{~cm}$ in nine months (274 days ). Zaidi bin Zakaria (2000) determined the age of the smallest oceanic squid $S$. oualaniensis of $10.7 \mathrm{~cm}$ as 102 day old. However, Zaidi bin Zakaria (2000) determined growth curves for both sexes and reported a female of $12.0 \mathrm{~cm}$ DML at 51 days of age. This suggests that environmental conditions such as temperature and food availability are the main factors influencing the growth rates, lifespan, and fluctuations of relative gonad investment.

\section{Medium form}

Growth coefficient of medium form was computed using Gulland and Holt plot as of $2.33 \mathrm{y}^{-1}$ with the $\mathrm{L}_{\infty}$ as $30.20 \mathrm{~cm}$ DML. Similarly, the $\mathrm{K}$ and $\mathrm{L}_{\infty}$ value computed in Fabens and Munro methods for the medium form were $2.68 \mathrm{y}^{-1}, 30.20 \mathrm{~cm}$ and $2.35 \mathrm{y}^{-1}, 29.65 \mathrm{~cm}$ DML respectively. The $\mathrm{K}$ and $\mathrm{L}_{\infty}$ computed using the length at age routine of the FiSAT were $2.19 \mathrm{y}^{-1}$ and $30.49 \mathrm{~cm}$ DML. The average $\mathrm{L}_{\infty}$ of all the five methods was $30.08 \mathrm{~cm}$ DML with the average $\mathrm{K}$ value of $2.38 \mathrm{y}^{-1}$ from the four methods. Growth performance index $(\pi)$ ranged from 3.3-3.39 with an average of 3.33 and the $t_{\text {max }}$ ranged from 408-500 days among the four methods with an average of 461 days. The $\mathrm{t}_{\max }$ was substantiated by the growth curve generated in the VBGF plot (Fig. 5) from the equation:

$L_{t}=30.2\left(1-\exp \left(-2.33\left(t-t_{0}\right)\right)\right.$

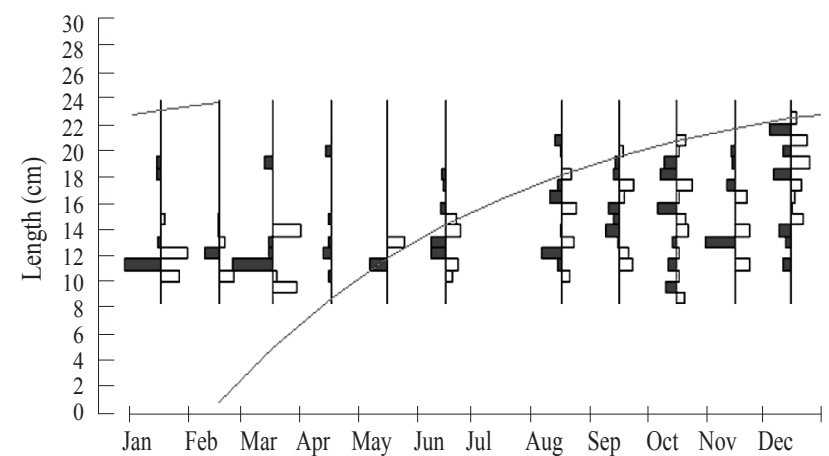

Fig. 5. von Bertalanfy growth curve for S. oualanienesis medium form with superimposed histograms. The dark and white bars are positive and negative deviations from the weighed model classes representing pseudo-cohorts
Fabens curve (Fig. 6.), indicated a slightly longer than a year life span for medium forms to attain $\mathrm{L}_{\infty}$. Zuyev et al. (1985) estimated the life span for the large, late-maturing form as 2 years using the von Bertalanffy growth equation. However, the study based on the gladius microstructure indicates that the duration of life cycle of middle-sized tropical, Red Sea and Arabian Sea forms are about 1 year (Zuyev et al., 2002).

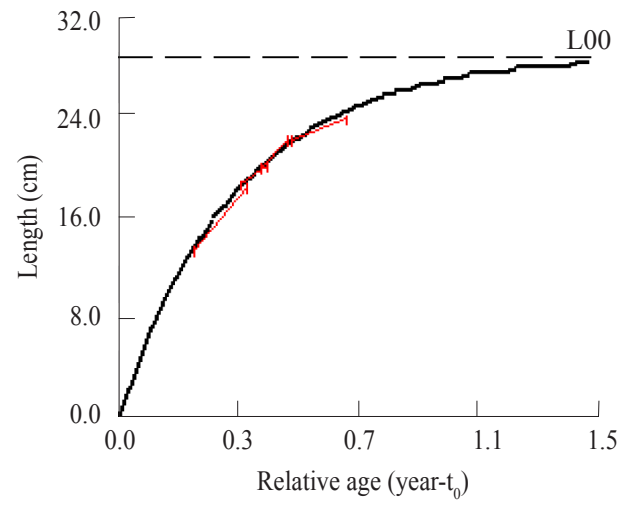

Fig. 6. Fabens growth curve for S. oualanienesis medium form

It is inferred from the growth curve that the growth is faster in the first half of the life when compared to the second half, as $63 \%$ of the growth is achieved in the first seven months time. However, it takes another seven months to achieve the remaining $37 \%$ of the growth indicating a slower later phase of growth. Medium form approximately grows to $13.3 \mathrm{~cm}$ DML in three months (91 days), $20.8 \mathrm{~cm}$ in six months (182 days) and $25.0 \mathrm{~cm}$ in nine months (273 days). Zaidi bin Zakaria (2000) estimated that female $S$. oualaniensis of $21.7 \mathrm{~cm}$ DML was 275 day old and male of $16.1 \mathrm{~cm}$ DML was 259 day old. Growth rate of the medium form computed from Gulland and Holt plot was 0.083 for the mean length of $16.89 \mathrm{~cm}, 0.068$ for mean length of $20.32 \mathrm{~cm}, 0.057$ for mean length of $22.23 \mathrm{~cm}$ and 0.029 for mean length of $24.13 \mathrm{~cm}$. This indicates a decreasing rate of growth from the juvenile to adult.

\section{Mortality parameters}

The total instantaneous mortality (Z) of the dwarf form was estimated as of $4.010 \mathrm{y}^{-1}$ (confidence interval of $Z=3.445-4.57$; standard deviation of the slope $=0.131 ; r=0.99)$ by the Jones and van Zalinge method (Fig. 7 and Table 2). However, Beverton \& Holt and Ault and Ehrhardt methods estimated the same as 5.419 and $4.299 \mathrm{y}^{-1}$ respectively. The average total mortality was computed as $4.57 \mathrm{y}^{-1}$.

In the medium form, total mortality coefficient $(\mathrm{Z})$ was estimated as $6.80 \mathrm{y}^{-1}$ using length-converted catch curve (Fig. 8) (confidence interval of $Z=5.0-8.6$; standard 


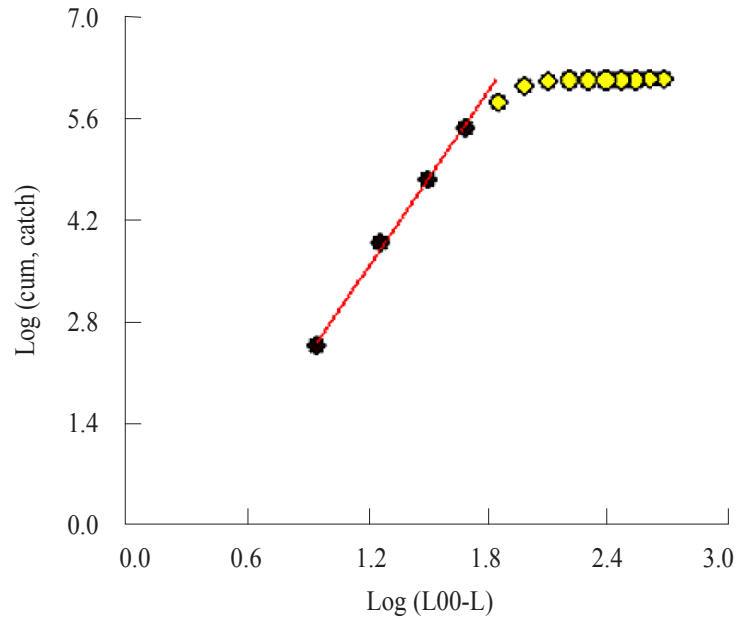

Fig. 7. Length based Jones and van Zalinga plot of Sthenoteuthis oualaniensis dwarf form for estimating total mortality

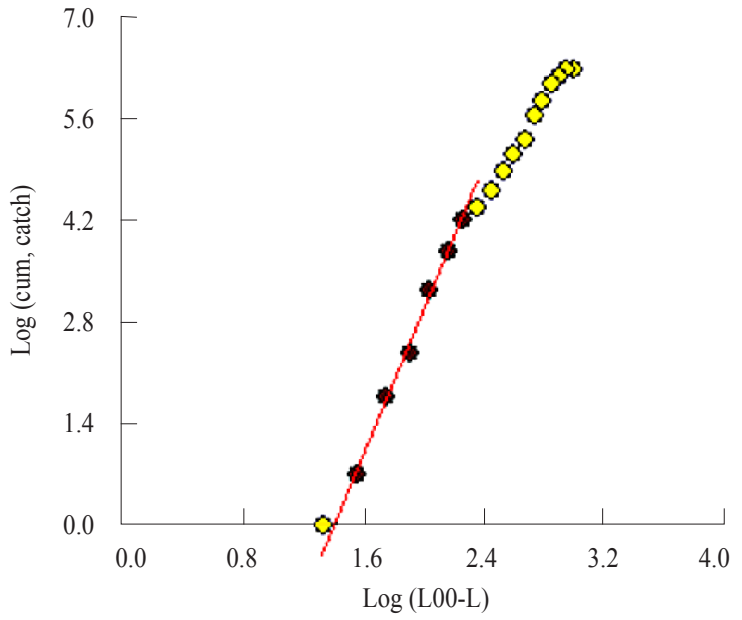

Fig. 9. Length based Jones and van Zalinge plot of Sthenoteuthis oualaniensis medium form for estimating total mortality

Table 2. Mortality parameters estimated for Sthenoteuthis oualaniensis of south-west coast of India

\begin{tabular}{|c|c|c|c|c|c|c|c|}
\hline \multirow{2}{*}{ Forms } & \multirow{2}{*}{ Parameters } & \multicolumn{4}{|c|}{ Models } & \multirow[b]{2}{*}{$\begin{array}{l}\text { Ault \& } \\
\text { Ehrhardt }\end{array}$} & \multirow{2}{*}{ Average } \\
\hline & & $\begin{array}{l}\text { Powell } \\
\text { Wetherall }\end{array}$ & $\begin{array}{l}\text { Length } \\
\text { converted } \\
\text { catch curve }\end{array}$ & $\begin{array}{l}\text { Jones \& van } \\
\text { Zalinge }\end{array}$ & $\begin{array}{l}\text { Beverton \& } \\
\text { Holt }\end{array}$ & & \\
\hline \multirow[t]{2}{*}{ Dwarf } & Z/ year & - & - & 4.010 & 5.419 & 4.299 & 4.576 \\
\hline & $\mathrm{Z} / \mathrm{K}$ & 3.215 & - & - & - & - & - \\
\hline \multirow[t]{2}{*}{ Medium } & Z/year & - & 6.80 & 4.906 & 6.227 & 6.177 & 6.027 \\
\hline & $\mathrm{Z} / \mathrm{K}$ & 3.191 & - & - & - & - & - \\
\hline
\end{tabular}

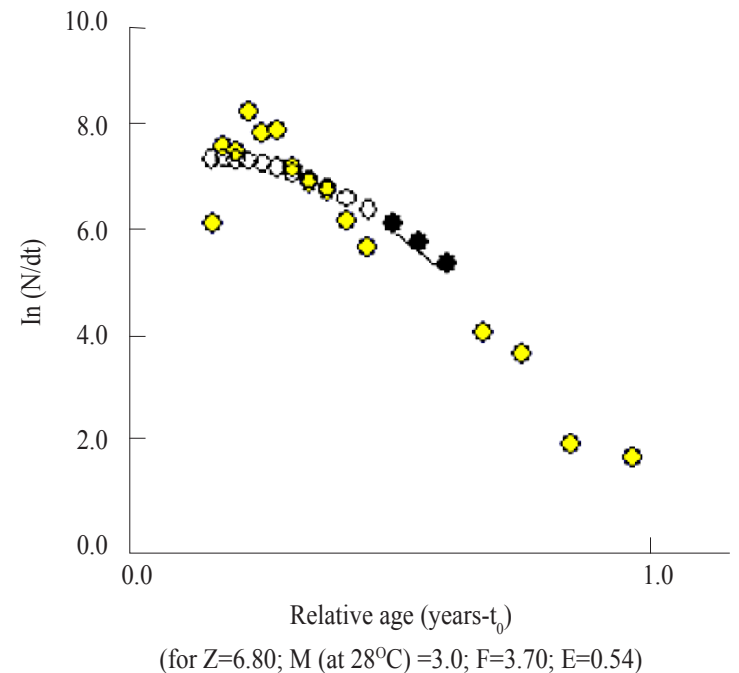

Fig. 8. Length converted catch curve of Sthenoteuthis oualaniensis medium form

deviation of the slope $=0.142 ; r=0.99$ ). While the total mortality coefficient computed by Jones and van Zalinge method (Fig. 9.) was $4.906 \mathrm{y}^{-1}$ (confidence interval of $Z=4.48-5.33$; standard deviation of the slope $=0.153$; $\mathrm{r}=0.99)$ and by Beverton \& Holt and Ault and Ehrhardt was 6.227 and $6.177 \mathrm{y}^{-1}$ respectively. The average total mortality rate was $6.02 \mathrm{y}^{-1}$. High rate of mortality in the short-lived species such as squids are quite natural (Caddy, 1983). Meiyappan and Srinath (1989) reported the total mortality of the Indian squid Loligo duvaucelli as high as $10.6 \mathrm{y}^{-1}$ at Cochin based on length converted catch curve method. The high mortality rate could be possibly due to faster growth, short life span, high level of cannibalism and possibly higher post-spawning mortality in S. oualaniensis.

From the present study it is evident that the growth, size and mortality parameters of the dwarf forms are clearly distinguishable from the medium forms of S. oualaniensis caught off the south-west coast of India.

\section{Acknowledgements}

Authors acknowledge the support and necessary facilities provided by the Director General and the Zonal Director of Fishery Survey of India. The first author is grateful to Dr. K. Sunil Mohamed, Head, Molluscan Fisheries Division, ICAR-Central Marine Fisheries 
Research Institute, Kochi, for critically going through the manuscript and for the constructive comments. The external assistance rendered by Mrs. Augusta Chembian is specially acknowledged.

\section{References}

Bettencourt, V. and Guerra, A. 2001. Age studies based on daily growth increments in statoliths and growth lamellae in cuttlebone of cultured Sepia officinalis. Mar. Biol., 139: $327-334$

Bhattacharya, C. G. 1967. A simple method of resolution of a distribution in to Gaussian components. Biometrics, 23: $115-135$

Bertalanffy, L. von 1951. Theoretische Biologie. Zweiter Band: Stoffwechsel, Wachstum.A, Francke AG Verlag, Bern, $418 \mathrm{pp}$.

Caddy, P. R. 1983. Advances in the assessment of world cephalopod resources. FAO Fish. Tech. Paper 231, Rome: $452 \mathrm{pp}$.

Chakraborty, S. K., Biradar, R. S., Jaiswar, A. K., Palaniswamy, R. and Pawan Kumar 2013. Growth, mortality and population parameters of three cephalopod species, Loligo duvauceli (Orbigny), Sepia aculeata (Orbigny) and Sepiella inermis (Orbigny) from north-west coast of India. Indian J. Fish., 60(3): 1-7, 2013.

Chembian, A. J. and Mathew, S. 2014. Population structure of the purpleback squid Sthenoteuthis oualaniensis (Lesson, 1830) along the south-west coast of India. Indian J. Fish., 61(3): 20-28, 2014.

Chung, W. S. and Lu, C. C. 2005. The influence of temperature and salinity on the statolith of the oval squid Sepioteuthis lessoniana Lesson, 1830 during early developmental stages. Phuket Marine Biological Centre Research Bulletin, 66: 175-185.

Clarke, M. R. 1965. Large light organs on the dorsal surfaces of the squids Ommastrephes pteropus, Symplectoteuthis oualaniensis and Dosidicus gigas. Proc. Malacol. Soc. Lond., 36, 319-321.

Clarke, M. R. 1983. Cephalopod biomass-estimation from predation. Memoirs of the National Museum of Victoria, 44: 95-107.

Forsythe, J. W. and Van Heukelem, W. F. 1987. Growth. In: Boyle. P. R. (Ed.) Cephalopod life cycles, Vol. 11: Comparative reviews. Academic Press. London, p. 135-156.

Hatfield, E. M. C. 2000. Do some like it hot? Temperature as a possible determinant of variability in the growth of the Patagonian squid, Loligo gahi (Cephalopoda: Loliginidae). Fish. Res., 47: 27- 40.

Hussy, K. 2008a. Otolith accretion rates: does size really matter? J. Exp. Mar. Biol. Ecol., 362: 131-136.
Hussy, K. 2008b. Otolith shape in juvenile cod (Gadus morhua): ontogenetic and environmental effects. J. Exp. Mar. Biol. Ecol., 364: 35-41.

Mehanna, S. F. and El-Gammal, F. I. 2010. Growth and population dynamics of the cuttlefish Sepia savignyi Blainville in the Gulf of Suez, Red Sea. Indian J. Fish., 57(1): 1-6, 2010

Meiyappan, M. M. and Srinath, M. 1989. Growth and mortality of the Indian squid (Loligo duvauceli) off Cochin, India. In: Venema, S. C. and VanZallnge, N. P. (Eds.), Contributions to tropical fish stock assessment in India. FAO, Rome, 157 pp.

Miyahara, K., Ota, T., Goto, T. and Gorie, S. 2006. Age, growth and hatching season of the diamond squid Thysanoteuthis rhombus estimated from statolith analysis and catch data in the western Sea of Japan. Fish. Res., 80: 211-220.

Mohamed, K. S. 1996. Estimates of growth, mortality and stock of the Indian squid Loligo duvauceli Orbigny, exploited off Mangalore, south-west coast of India. Bull. Mar. Sci. 58(2): 393-403.

Mohamed, K. S., Joseph, M. and Alloycious, P. S. 2006. Population characteristics and some aspects of the biology of oceanic squid Sthenoteuthis oualaniensis (Lesson, 1830). J. Mar. Biol. Assoc. India, 48(2): 256-259.

Morris, C. C. 1991. Methods for in situ experiments on statolith increment formation, with results for embryos of Alloteuthis subulata. In: Jereb, P., Ragonese, S. and von Boletzky (Eds.), Squid age determination using statoliths, N.T.R.-Instituto di Tecnologia della esca e del Pescato Spec. Publ. 1, Mazara del Vallo, Italy: p. 67-72.

Nesis, K. N. 1977. Population structure in the squid Sthenoteuthis oualanienses (Lessonn, 1930) (Ommastrephidae) in the Western Tropical Pacific. In: Proceedings of the Academy of Science USSR, Shirsch Inst. Oceanol., 107: 15-29.

Nesis, K. N. 1993. Population structure of oceanic Ommastrephids, with particular reference to Sthenoteuthis oualaniensis: a review. In: Okutani, T., O'Dor, R. K. and Kubodera, T. (Eds.), Population structure of oceanic Ommastrephids, with particular reference to Sthenoteuthis oualaniensis: a review. Recent advances in fisheries biology. Takai University Press, Tokyo, p.375-383.

Pauly, D. 1984. Length-converted catch curves: a powerful tool for fisheries research in the tropics (Part II). ICLARM Fishbyte, 2(1): 17-19.

Pauly, D. 1998. Why squids, though not fish, can be better understood by pretending they are. S. Afr. J. Mar. Sci., 20: 47-58.

Radtke, R. L. 1983. Otolith formation and increment deposition in laboratory-reared skipjack tuna (Euthynnus pelamis), larvae. In: Prince, E. D. and Pulos, L. M. (Eds.) Proceedings of the international workshop on age determination of oceanic pelagic fishes; tunas, billfishes, 
and sharks. United States Department of Commerce, NOAA Technical Report 8, p. 99-103.

Roper, C. F. E., Sweeney, M. J. and Nauen, C. E. 1984. FAO species catalogue, vol. 3. Cephalopods of the world. An annotated and illustrated catalogue of species of interest to fisheries. FAO Fish. Synop., (125) 3: 277 pp.

Sinclair, A. F. 2001. Natural mortality of cod (Gadus morhua) in the Southern Gulf of St Lawrence. ICES J. Mar. Sci., 58: 1-10, 2001.

Sparre, P. and Venema, S. C. 1996. Introduction to tropical fish stock assessment. Part I -Manual. FAO Fish. Tech. Paper, 306/1. 375 pp.

Trotsenko, B. G. and Pinchukov, M. A. 1994. Mesoscale distribution features of the purpleblack squid Sthenoteuthis oualaniensis with reference to the structure of the upper quasi-homogeneous layer in the West India Ocean. Oceanology, 34(3): 380-385.

Verrill, A. 1882. Report on the cephalopods of the north-eastern coast of America.US Comm. Fisheries Reports, 7: 211-455.

Villanueva, R. 2000. Effect of temperature on statolith growth of the European squid Loligo vulgaris during early life. Mar. Biol., 136: 449-460.

Wormuth, J. H. 1976. The biogeography and numerical taxonomy of the Oegopsid squid family Ommastrephidae in the Pacific Ocean. Bull. Scripps Inst. Oceanogr., 23: 1-89.

Xinjun, C., Bilin, L., Siquan,T., Weiguo, Q. and Xiaohu, Z. 2007. Fishery biology of purpleback squid, Sthenoteuthis oualaniensis, in the north-west Indian Ocean. Fish. Res., 83: 98-104.

Yatsu, A. 2000. Age estimation of four oceanic squids, Ommastrephid bartramii, Dosidicus gigas, Sthenoteuthis oualaniensis and Illex argentinus (Cephalopoda: Ommastrephidae) based on statolith microstructure. Japan Int. Res. Cent. Agr. Sci., 34(1): 75-80.

Zaidi bin Zakaria, M. 2000. Age and growth studies of oceanic squid, Sthenoteuthis oualaniensis using statoliths. In: Proceedings of the Third Technical Seminar on marine fishery resources survey in the South China Sea, Area III: Western Philippines. Special Paper No. SEC/ $S P / 41$. South-east Asian Fisheries Development Center, Bangkok. 336 pp.

Zuev, G. V., Nigmatidlin, C. and Nikolsky,V. N. 1985. Nectonic oceanic squid (genus Sthienoteuthus). Moscow: Agropromizdat, 224 pp. (in Russian)

Zuev, G. V., Nigmatullin, C., Chesalin, M. and Nesis, K. N. 2002. Main results of long-term worldwide studies on tropical nektonic oceanic squid genus Sthenoteuthis: an overview of the Soviet investigations. Bull. Mar. Sci., 71(2): 1019-1060. 